Article

\title{
Analysis of Environmental Policy and the Performance of Sustainable Agricultural Development in China
}

\author{
Guofeng Wang ${ }^{1}$, Ziyu Qian ${ }^{1}$ and Xiangzheng Deng ${ }^{2,3,4,5, *}$ \\ 1 Faculty of International Trade, Shanxi University of Finance and Economic, Taiyuan 030006, China; \\ wanggf@sxufe.edu.cn (G.W.); qianziyu0604@163.com (Z.Q.) \\ 2 Institute of Geographic Sciences and Natural Resources Research, Chinese Academy of Sciences, \\ Beijing 100101, China \\ 3 Center for Chinese Agricultural Policy, Chinese Academy of Sciences, Beijing 100101, China \\ 4 University of Chinese Academy of Sciences, Beijing 100149, China \\ 5 Key Laboratory of Land Surface Pattern and Simulation, Chinese Academy of Sciences, Beijing 100101, China \\ * Correspondence: dengxz@igsnrr.ac.cn
}

Received: 31 October 2020; Accepted: 10 December 2020; Published: 14 December 2020

check for updates

\begin{abstract}
A community with a shared future for mankind embodies the concept of sustainable development. This is also China's contribution to global governance. Some of the Sustainable Development Goals (such as the elimination of hunger and malnutrition) require countries to implement people-centered overall agricultural transformations, and achieving such agricultural transformations is key to ensuring sustainable agricultural development and shifting agriculture toward a greener and more ecological direction. This paper uses the SBM Directional Distance Function and Malmquist Productivity Index with calculated data from 2000 to 2016. The results show that, since 2000, China's environmental performance index growth has been slow, with an average annual growth rate of only $0.80 \%$. This growth has gone through three phases: a stable up and down phase, a volatility decrease phase, and a volatility increase phase. In general, agricultural technological advances have played a more visible role in promoting a strong performance in reducing carbon emissions. Agriculture in China is also on the way to becoming more sustainable and green.
\end{abstract}

Keywords: sustainable development; environment policy; environmental performance index (EPI); SBM-undesired output

\section{Introduction}

The concept of a community with a shared future for mankind is an important idea that meets the practical needs of sustainable development. Since putting forward the concept of a human community with the "area" initiative, a series of enriched concepts of global cooperation has gradually become socially recognized internationally by way of innovation and development to achieve global ecological harmony [1]. This type of international peace, as a core principle, embodies China's role in global sustainable development [2]. The United Nations Sustainable Development Goals (SDGs) regard the elimination of poverty and zero hunger as the first and second key goals of global sustainable development $[3,4]$, reflecting the important role of agriculture in the whole process of human development [5]. As a vital part of world agriculture, China's agriculture plays a very important role in the process of human development [6]. Under new situations of development and to determine how to achieve a sustainable transformation of China's agriculture under the complex environments both at home and abroad, the relevant environmental policies to be adopted must be effectively screened [7]. From the perspective of the current development situation, China's agriculture is facing 
large opportunities for development. Due to the pace of China's rapid urbanization in promoting the rural one-way flow into the city, many rural areas have become "hollow villages" with a lack of young adults and a series of other problems [8]. However, at the same time, China's rural areas are very resource-rich and have vast areas of land, a good ecological environment, diversified products for agricultural production [9], and are able to achieve agriculturally sustainable development [10]. From the perspective of international sustainable agricultural development, sustainable development depends on agricultural transformation [11]. Modern agriculture in the United States adopts the development mode of large-scale, mechanized, and high-tech agriculture and applies technological innovation as an inexhaustible driving force for sustainable agricultural development [12]. Japan employs resource conservation alongside capital and technological investments to develop its modern agriculture. In terms of agricultural sustainability, Japan uses the mode of "green payment" to realize compensation and maintains agricultural sustainability mainly by paying farmers to produce agricultural products in pollution-free industries [13]. The irrigated agriculture of Israel, the efficient and refined agriculture of the Netherlands, and the environmentally friendly and ecological agriculture of France also provide important models for the sustainable development of China's agriculture [14].

China's agricultural development has entered a new period due to the opportunity for modernization and development. Moreover, the traditional agricultural growth mode is in urgent need of a new transformation [15]. Therefore, in the context of resource and environmental constraints, determining how to construct environmental policies for sustainable agricultural development has become vital for rural revitalization [16]. Policy science is the study of a series of interrelated policies in the fields of production, organization, resource allocation, factors of production, and product circulation. To adapt to the development of the rural contract responsibility system, tax and fee reform, urban-rural integration, and other stages, China's agricultural policy science has become a guide for the sustainable development of agriculture [17], highlighting the policy and reform paths in different periods. China's agricultural and environmental policy has gradually matured along with the historical context of the No. 1 Document of the CPC Central Committee. From 1982 to 2018, the No.1 Document of the CPC Central Committee followed the historical development trends, focusing on issues related to agriculture, rural areas, and farmers [18] and endeavoring to solve developmental problems. In 1982, the No. 1 Document of the CPC Central Committee officially recognized the legal quota for each household, indicating that the country's development focus began to shift toward agriculture. With the development of China's national conditions, the theme involved in the No. 1 Document of the Central Committee became gradually diversified. This development can be divided into five stages: The second stage (2004-2007) mainly focused on how to increase farmers' income and stabilize production capacity; the third stage (2008-2012) focused on ensuring agricultural production conditions and developing agricultural infrastructure and science and technology; the fourth stage (2013-2020) has developed modern agriculture and promoted the development of green, organic, and pollution-free agriculture. Overall, the strategy for sustainable rural revitalization is related to the large differences in urban and rural resources and environments, the balanced development of food security, industrial income increases and ecological protection, and the principle of taking step-by-step measures according to local conditions. However, agriculture in China faces some challenges, such as the degradation of land production capacity caused by continuous increases in production and the increase in agricultural carbon emissions caused by the use of fertilizers and pesticides, which pose a serious threat to the sustainable transformation of agriculture.

Scholars have widely measured performance in the process of agricultural production [19-21]. However, there is no consensus on the performance of the agricultural environment concept. Scholars have adopted agricultural ecological efficiency, agricultural carbon emission efficiency, and even agricultural carbon intensity as indicators to measure this concept. Thus, the methods are diverse, especially the use of non-parameter methods, which are typical in data envelopment analysis, and the parameter method, which is typical of stochastic frontier analysis [22]. When considering the measurement of the agricultural production process, the work of previous scholars did not fully 
consider environmental factors; however, a lack of environmental factors will make agricultural production performance measurements significantly higher, resulting in errors [23]. Scholars generally understand environmental factors in one of three ways. The first is to regard them as inputs, the second is to regard them as the same free disposal output as the expected output, and the third is to regard them as weak disposal of the unexpected output. This study draws on the previous research results and introduces the concept of undesired output into the measurement of agricultural environmental performance. This paper measures China's agricultural environmental performance from 2000 to 2016 and determines the overall pattern of change through the development of the growth situation. The innovation of this study lies in its use of agricultural environmental performance as the key variable of agricultural transformation, taking agricultural carbon emissions as an unexpected output in the measurement process and exploring agricultural transformation.

\section{Methods and Data}

This study uses the work of Fare (2007) [24-26] based on the basic principles of low carbon emission production technology. Suppose that there are $N$ input factors $x$ and the desired output $y$ along with an undesired output (such as wastewater, solid waste, greenhouse gas emissions, etc.):

$$
\left\{\begin{array}{c}
x=\left(x_{1}, x_{2}, \ldots, x_{N}\right) \in R_{+}^{N} \\
y=\left(y_{1}, y_{2}, \ldots, y_{N}\right) \in R_{+}^{M} \\
b=\left(b_{1}, b_{2}, \ldots, b_{N}\right) \in R_{+}^{I}
\end{array}\right.
$$

Then, the production possibilities set for low-carbon production technologies are as follows:

$$
P(x)=\{(y, b): x \text { can produce }(y, b)\}, x \in R_{+}^{N}
$$

The production set $P(x)$ should meet the following conditions. $P(x)$ is a bounded closed set, which indicates that a limited input can only produce a limited output under the environmental production technology condition $P(x)$. In other words, in the case of a certain input of factors of production, the output must be limited. Here, the reduction in non-consensual output under a given input occurs at the expense of a desirable output, and the reduction in the two may be consistent over the same period. Moreover, the zero-combination of desired output and undesired output [27] (i.e., the production of expected output) is necessarily accompanied by an unexpected output, and the only way to avoid the emergence of an undesirable output is to stop all productive activities:

$$
\left\{\begin{array}{l}
P(x) \text { is compact } x \in R_{+}^{N} \\
(y, b) \in P(x) \text { and } y^{\prime} \leq y \text { imply }\left(y^{\prime}, b\right) \in P(x) \\
(y, b) \in P(x) \text { and } c^{\prime} \leq c \text { imply }\left(y^{\prime}, b\right) \notin P(x) \\
(y, b) \in P(x) \text { and } b=0 \text { imply } y=0
\end{array}\right.
$$

In the actual operations and calculations, the above ideas can be concretized with the Data Envelopment Analysis (DEA) method, i.e., expressed through DEA by "assuming that during a period, there is a production unit in the input variable $t=1, \ldots, T$, which has $k=1, \ldots, K$ units of production and the input variable is $\left(x_{k^{\prime}}^{t} y_{k^{\prime}}^{t} b_{k}^{t}\right)$; then, the production process can be described" as the following with constant scale compensation:

$$
P^{t}\left(x^{t}\right)=\left[\begin{array}{l}
(y t, b t): \sum_{k=1}^{K} z_{k}^{t} y_{k, m}^{t} \geq y_{m}^{t}, m=1, \ldots, M ; \\
\sum_{k=1}^{K} z_{k}^{t} b_{k, i}^{t}=b_{i}^{t}, i=1, \ldots, I ; \\
\sum_{k=1}^{K} z_{k}^{t} x_{k, n}^{t} \leq x_{n}^{t}, n=1, \ldots, N ; z_{k}^{t} \geq 0, k=1, \ldots, K
\end{array}\right]
$$




\subsection{SBM Directional Distance Function}

The DEA model mostly takes the form of radial and linear segmentation, which effectively guarantees an increase in production possibilities. However, when there is over-input ("crowded") or insufficient output, the radial DEA overestimates the efficiency of the production unit [28]. A strict state of full efficiency should have neither radial inefficiency nor a lack of input or output. With reference to the input and output relaxation in the target function, Tone (2001) proposed a non-radial non-angle-based relaxation-based efficiency model, which effectively solves the above defects [29]. Tone further demonstrated that SBM is valid only if the CCR is valid (when relaxation is 0 ) and the SBM efficiency value is less than or equal to the CCR efficiency value. Drawing on Tone $(2001,2003)$, the non-radial non-angle SBM directional distance function model of the production unit $k^{\prime}\left(x_{k^{\prime}}^{t} y_{k^{\prime}}^{t}, t_{k}^{t}\right)$ in period $t$ contains non-consensual output:

$$
\begin{gathered}
\overrightarrow{S_{c}^{t}}\left(x_{k^{\prime}}^{t}, y_{k^{\prime}}^{t}, b_{k}^{t}\right)=p^{*}=\min \frac{1-\left[\frac{1}{N} \sum_{n=1}^{N} s_{n}^{x} / x_{n}^{k}\right]}{1+\left[\frac{1}{M+1}\left(\sum_{m=1}^{M} s_{m}^{y} / y_{m}^{k}+\sum_{m=1}^{I} s_{i}^{b} / b_{i}^{k}\right)\right]} ; \\
\text { s.t. } \sum_{k=1}^{K}=z_{k}^{t} y_{k, m}^{t}-s_{m}^{y}=y_{k, m^{\prime}}^{t} m=1, \ldots, M ; \\
\sum_{k=1}^{K}=z_{k}^{t} b_{k, i}^{t}-s_{i}^{b}=b_{k, m^{\prime}}^{t} i=1, \ldots, I ; \\
\sum_{k=1}^{K}=z_{k}^{t} x_{k, m}^{t}-s_{n}^{y}=x_{k, m^{\prime}}^{t} n=1, \ldots, N ; \\
z_{k}^{t} \geq 0, s_{m}^{y} \geq 0, s_{i}^{b} \geq 0, s_{n}^{y}>0, k=1, \ldots, K
\end{gathered}
$$

where the value of the objective function directly contains the amount of input and output $s^{x}$ relaxation. $s^{y}$ and the output $s^{b}$, respectively, indicate the excess input and the output that is insufficient, effectively solving the problem of output and output relaxation. $p^{*}$ strictly decreases with respect to $s^{x}, s^{y}$, and $s^{b}$, as well as $p^{*} \in[0,1] \cdot p^{*}=1$ only when the production unit is fully efficient. At this $s^{x}=s^{y}=s^{b}=0$ time, there is no excess input and insufficient output in the optimal solution. In addition to considering the impact of environmental pollution losses and slack, the model also has non-angular properties, taking into account the reduction in inputs and the increase in output.

\subsection{Malmquist Productivity Index}

Based on the human studies of Chung et al. (1997), the Malmquist Productivity Index measure includes the full factor productivity of undesired outputs [30,31]. Referring to the concept of cross-period dynamics with reference to the Malmquist index geometric mean, we constructed the all-factor productivity index from period $t$ to $t-1$ based on the multiplication structure and the SBM directional distance function of adjacent references, defined as agricultural environmental performance (AEP):

$$
\mathrm{AEP}=M_{0}\left(x^{t}, y^{t}, x^{t+1}, y^{t+1}\right)=\frac{D_{0}^{t+1}\left(x^{t+1}, y^{t+1}\right)}{D_{0}^{t}\left(x^{t}, y^{t}\right)} \times\left[\frac{D_{0}^{t}\left(x^{t+1}, y^{t+1}\right)}{D_{0}^{t+1}\left(x^{t+1}, y^{t+1}\right)} \times \frac{D_{0}^{t}\left(x^{t}, y^{t}\right)}{D_{0}^{t+1}\left(x^{t}, y^{t}\right)}\right]^{\frac{1}{2}}
$$

where $D_{0}^{t}\left(x^{t}, y^{t}\right)$ represents the level of efficiency of the current period expressed by the technology in $t$-period;

$D_{0}^{t+1}\left(x^{t+1}, y^{t+1}\right)$ represents the level of efficiency for the current period expressed by the technology in $t-1$ period;

$D_{0}^{t}\left(x^{t+1}, y^{t+1}\right)$ represents the level of efficiency of issue $t+1$ represented by the technology of issue $t$ (i.e., the data for period $t$ as a reference set);

$D_{0}^{t+1}\left(x^{t}, y^{t}\right)$ represents the level of efficiency in the $t$-period represented by the technology of the period (i.e., the data for period $t-1$ as a reference set). 
Based on this, it can be clearly determined that the changes in the Malmquist Productivity Index consist of two parts: The first includes the technical efficiency changes from the $t$-period to $t-1$ period, and the second involves a change in technological progress from $t$-phase to $t-1$.

AEP represents the performance of the agricultural environment from $t$ to $t-1$, which can be broken down into the Technology Efficiency Change Index (EFF) and the Technology Progress Index (TECH). TECH can be further divided into pure efficiency changes (PECH) and scale efficiency changes $(\mathrm{SECH})$. AEP $>1$ indicates an increase in the carbon performance index, which then decreases. EFF $>1$ means that technological efficiency has improved, while tech $<1$ indicates technological progress at the forefront of agriculture and vice versa.

\subsection{Research Data}

According to the literature review and the previous research results [32,33], a scientific and reasonable input and output index evaluation system for agricultural production efficiency was constructed (Table 1). Through the establishment of the index system, a foundation and guarantee were provided for the objective evaluation of agricultural production efficiency. According to the definition of agricultural production efficiency in the literature review, the evaluation system of production efficiency was constructed by following the principle of index evaluation system selection (based on accessibility, scientific value, purpose, etc.) in the literature review. The decision-making unit (DMU) was taken as one of the 31 provinces (cities and districts) in China (not including Hongkong, Taiwan, or Macao).

Table 1. Indicators of inputs and outputs.

\begin{tabular}{|c|c|c|c|}
\hline & Variable & Index & Unit \\
\hline \multirow[t]{6}{*}{ Input indicators } & Labor input & $\begin{array}{l}\text { Number of workers employed in } \\
\text { the tertiary sector }\end{array}$ & Tens of thousands of people \\
\hline & Land input & Crop planting area & Thousand hectares \\
\hline & & $\begin{array}{l}\text { Pure amount of } \\
\text { agricultural fertilizer }\end{array}$ & Tons \\
\hline & & Pesticide use & Tons \\
\hline & & Agricultural film usage & Tons \\
\hline & & $\begin{array}{l}\text { Total power of } \\
\text { agricultural machinery }\end{array}$ & $10,000 \mathrm{kWh}$ \\
\hline \multirow[t]{2}{*}{ Output indicators } & \multicolumn{2}{|c|}{$\begin{array}{c}\text { Total output value of agriculture, forestry, animal } \\
\text { husbandry, and fishing }\end{array}$} & Billions of dollars \\
\hline & \multicolumn{2}{|c|}{ Agricultural carbon emissions } & Tons \\
\hline
\end{tabular}

Input index: The selected input indexes in this paper are mainly divided into labor input, land resource input, and agricultural consumption resource input under three categories. These categories include labor input to the provinces (cities, districts) based on of the number of agricultural primary industry workers (units: 10,000 people); land input indicators selected while taking into account different regional replanting indexes and the actual phenomenon of fallow and abandoned land; and the land seed area selected as a land resource input variable (units: thousands of hectares). The input index variable mainly uses the amount of agricultural fertilizer purification, pesticide usage, and the amount of agricultural film used in the year. In terms of mechanical input (mainly to the provinces) (cities, districts), the total power of agricultural machinery is used as the calculation variable (units: 10,000 kilowatts), while the irrigation input considers the inaccessibility of irrigation water. This paper uses the provinces (cities, districts) for the effective irrigation variable area each year.

Output index: The purpose of this paper is to measure the agricultural carbon emission performance index. For this reason, there are two output variables: one for the agriculture, forestry, and fishery output value and the other, which is undesired (i.e., agricultural carbon emissions). 
The data used in this paper come from the China Rural Statistics Yearbook 2000-2017, the Compilation of Agricultural Statistics for the 30 Years of Reform and Opening-up, the Compilation of 60 Years of Statistics for New China, and the Yearbook of the Provinces and Municipalities. Among them, the amount of agricultural fertilizer conversion, pesticide use, agricultural film use, crop seeding area, total power of agricultural machinery and effective irrigation area, and rural first-industry working population are subject to the actual situation of the current year. The analysis in this section covers only 31 provinces, municipalities, and autonomous regions due to the accessibility of data.

In 2016, China's total carbon emissions were 272.022 million tons, which is $26.67 \%$ more than that in 2000 (Figure 1), with an average annual increase of $1.67 \%$. The carbon emissions caused by land use, rice planting, and livestock and poultry totaled 110.5649, 70.193, and 91.2642 million tons, respectively, accounting for $40.64 \%, 25.8 \%$, and $33.55 \%$ of the agricultural carbon emissions.

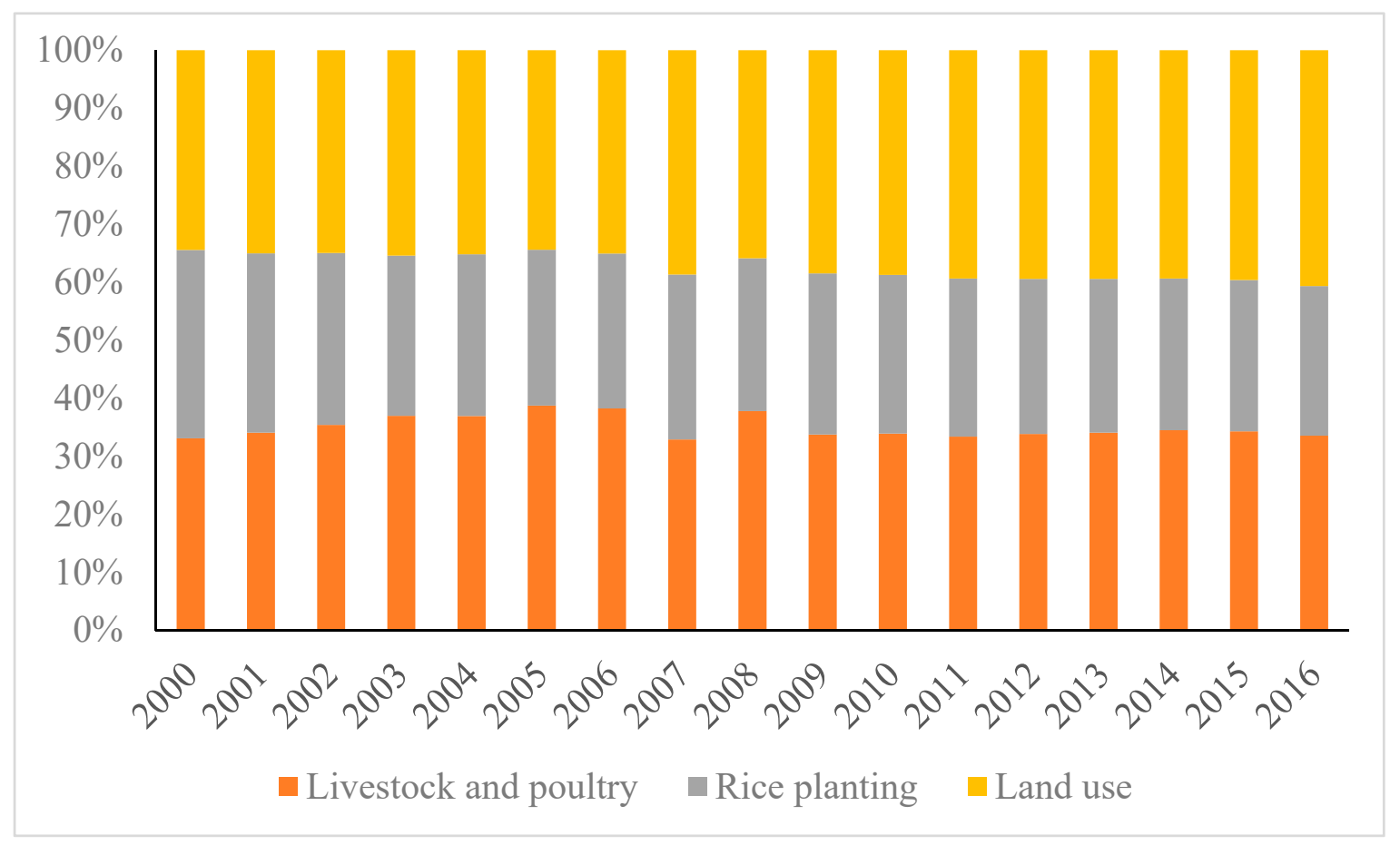

Figure 1. Agricultural carbon emission in China from 2000 to 2016.

\section{Results}

\subsection{Growth and Sources of Agricultural Environmental Performance in China}

Based on the low-carbon agricultural productivity growth and sources of China, under low-carbon constraints, China's low-carbon agricultural production rate growth since 2000 has been slow (Table 2). Based on the sources of growth, which mainly rely upon agricultural frontier technological progress, China's average annual contribution rate is $0.76 \%$.

The agricultural environmental performance indicators for 2001, 2003, 2004, 2006, 2009, and 2012 are all below 1.0 (Figure 2), indicating that agricultural development in China deteriorated during these years; for 2000, 2002, 2005, 2007, 2008, 2010, 2011, 2013, 2014, 2015, and 2016, the agricultural environmental performance indicators are above 1.0, indicating that China's agricultural development improved during these years. The highest agricultural environmental performance index in 2014 was 1.0617, indicating that China's low-carbon agricultural production level was greatly improved in this year, with an increase of 6.17 percent compared to the previous year. In terms of technical efficiency, the highest in 2014 was 1.0387, indicating that the improvement in agricultural technical efficiency played an important role in promoting low-carbon agricultural development during that year (its contribution rate reached 3.87 percent). At a technical level, the increase in 2011 was the 
most obvious. The improvement in China's low-carbon agricultural development during the year of agricultural frontier technology reached $9.25 \%$, and the lowest value was observed for 2004 at only 0.9257. This year's agricultural technological changes not only failed to promote China's low-carbon agricultural development but also made it deteriorate greatly, leading to the lowest level of the low-carbon agricultural production rate in China (2000-2016; 0.9555).

Table 2. Growth in agricultural environmental performance and changes in sources.

\begin{tabular}{cccccc}
\hline Year & EFF & TECH & PECH & SECH & AEP \\
\hline 2000 & 0.9852 & 1.0484 & 0.98097 & 0.9954 & 1.0329 \\
2001 & 1.0275 & 0.9625 & 1.0176 & 1.0097 & 0.989 \\
2002 & 0.9786 & 1.038 & 0.9836 & 0.9949 & 1.0157 \\
2003 & 1.0104 & 0.9601 & 1.0064 & 1.004 & 0.9702 \\
2004 & 1.0322 & 0.9257 & 1.0143 & 1.0177 & 0.9555 \\
2005 & 0.9845 & 1.0216 & 0.9918 & 0.9927 & 1.0058 \\
2006 & 0.9916 & 0.9997 & 0.9981 & 0.9936 & 0.9912 \\
2007 & 0.9942 & 1.0386 & 0.995 & 0.9991 & 1.0326 \\
2008 & 1.0124 & 1.0487 & 1.0095 & 1.0028 & 1.0616 \\
2009 & 0.9924 & 0.9919 & 0.9844 & 1.0081 & 0.9843 \\
2010 & 1.0036 & 1.0222 & 1.0049 & 0.9987 & 1.0259 \\
2011 & 0.9594 & 1.0925 & 0.9752 & 0.9838 & 1.0483 \\
2012 & 1.0008 & 0.968 & 0.9995 & 1.0014 & 0.9688 \\
2013 & 1.0034 & 0.9996 & 1.0069 & 0.9965 & 1.0029 \\
2014 & 1.0387 & 1.0221 & 1.0226 & 1.0158 & 1.0617 \\
2015 & 0.9941 & 1.0206 & 0.9926 & 1.0015 & 1.0145 \\
2016 & 1.0075 & 1.0282 & 1.0062 & 1.0013 & 1.0359 \\
\hline
\end{tabular}

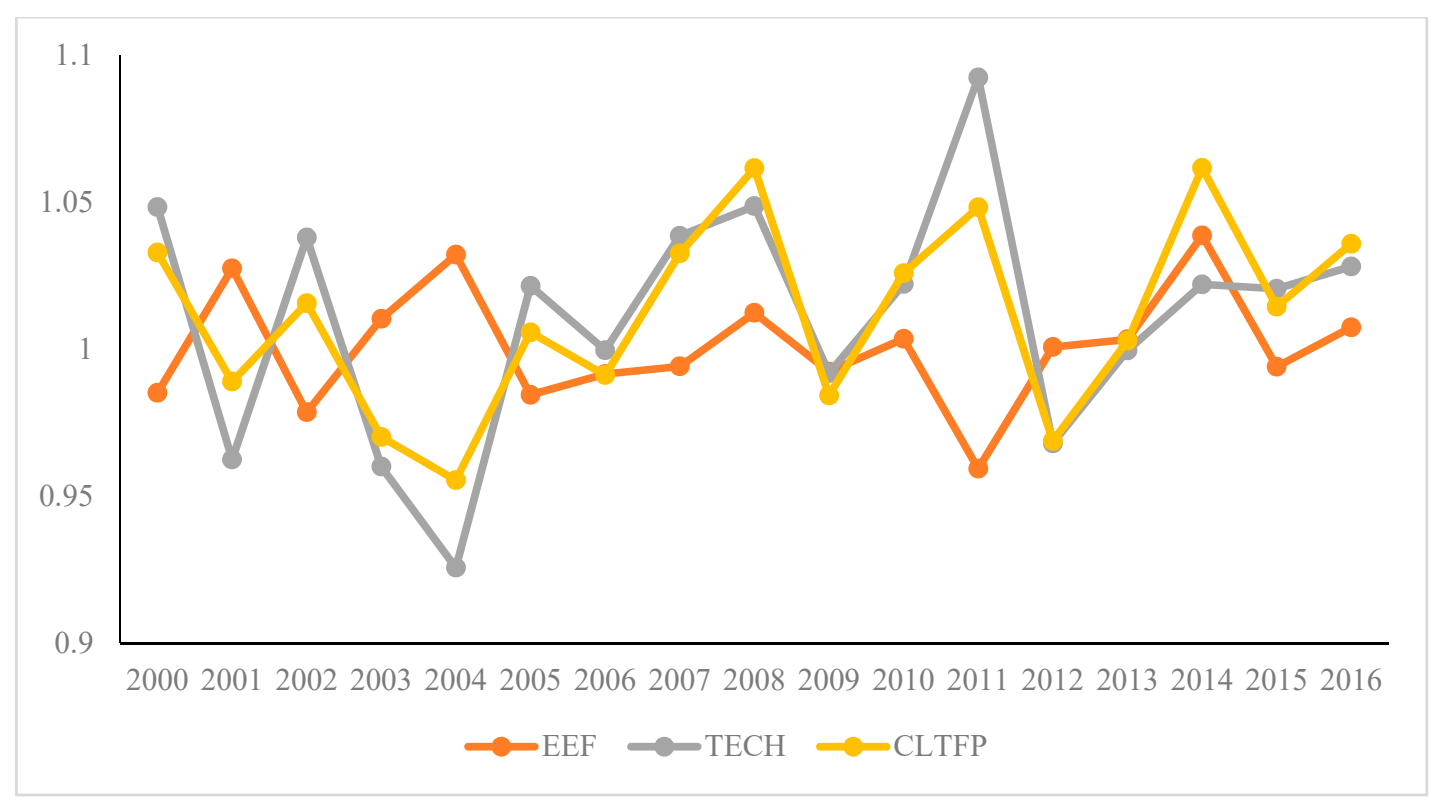

Figure 2. Growth in agricultural environmental performance and changes in sources.

\subsection{Environment Time Series Characteristics of Performance Changes}

Since 2000, China's agricultural development has passed through three stages: a stage of steady fluctuation, a stage of fluctuation, and a rising stage.

2000-2002 was a period of steady fluctuation. Although there were some fluctuations in the development levels of low-carbon agriculture during this period, the inter-year changes were not notable. Specifically, the 2001 Environmental Performance Index was below 1.0 at 0.9890 , and in 
2000 and 2002, the low-carbon agricultural productivity was higher than 1.0, followed by 1.0329 and 1.0157. At this stage, China's agricultural development experienced a period of rapid increase, except in 2001. In the other years, the gross output value growth for the agricultural, forestry, animal husbandry, and fishery industries (excluding price impact) indicated a real growth rate of more than $6 \%$. The development of the cultivation industry, especially the increase in grain production, mainly depends on a large amount of input of agricultural materials, such as fertilizers and pesticides. However, the increase in output also increased greenhouse gas emissions, thus increasing carbon emissions to a certain extent. As a result, increased carbon emissions from livestock farming affected agricultural carbon emissions.

In 2002-2006, China experienced a decline in volatility in addition to a slight rebound in 2005. In the other years, low-carbon agricultural productivity was lower than 1 compared to the previous year, indicating a downward trend. Thus, China's agricultural growth slowed significantly, and the annual growth rates of agriculture, forestry, animal husbandry, and fisheries were less than $5 \%$. This was related to the heavy environmental burden of the "three agricultural problems", further highlighted by farmers. This not only affected the agricultural economic output, resulting in a slow growth rate in the total output value of the planting industry, but also greatly affected the agricultural ecological output. The reduction in grain production led to a decline in China's agricultural carbon emissions at this stage - a disadvantage that greatly affected the performance of carbon emissions. At the same time, the continuous increase in large livestock and pig breeding steadily increased the carbon emissions caused by livestock and poultry breeding, which also affected China's agricultural development.

The period of 2006-2016 was a period of volatility, during which most annual carbon emission performance indexes were higher than 1.0. In 2008 and 2014, this index was greater than 1.05 with 1.0616 and 1.0617, respectively. During these 10 years, only in 2009 and 2012 was the environmental performance less than 1.0 - down by $1.57 \%$ and $1.12 \%$, respectively, from the previous year. The environmental performance in other years was higher than 1.0, which shows that although there were some ups and downs in China's low-carbon agricultural development at this stage, the overall upward trend was more obvious. At this stage, China's total output value of agriculture, forestry, animal husbandry, and fisheries showed a relatively stable upward trend. The average annual growth rate was more than 4-6\%-slightly slower than the first stage but faster than the second stage. Since 2004, the "benefit agriculture type" central document outlined factors related to rural productivity, enhanced the enthusiasm of farmers, and greatly improved the agricultural production level. Subsequently, the grain production achieved a record high with an unprecedented "ten consecutive increases". On the other hand, agricultural carbon emissions also experienced a period of rapid increase. Of course, this is only part of the reason for the improvement in carbon emission performance; another key reason is the continuous optimization of China's animal husbandry industry structure. At this stage, China's animal husbandry industry maintained a good developmental trend. The total output value reached a new level. Importantly, the resulting greenhouse gas emissions did not keep pace with the total value of animal husbandry but instead showed a decoupling state. This occurred primarily because at this stage, China's animal husbandry industry structure was greatly optimized, thereby reducing the number of large livestock and increasing the low emissions/high value-added livestock and poultry breeding efforts, which not only ensured the output of animal husbandry but also somewhat reduced greenhouse gas emissions to help achieve low-carbon development of the industry.

\subsection{Environmental Performance Index Growth Sources and Evolution Characteristics}

Based on the sources of growth in environmental performance over the years, 2001, 2003, 2004, 2012, and 2013 relied entirely on improvements in agricultural technical efficiency, while the role of pure technical efficiency and scale efficiency was roughly the same; conversely, cutting-edge technologies were degraded during this period. The years of 2000, 2002, 2005, 2007, 2011, and 2015 experienced advances only in cutting-edge agricultural technology, with technical efficiency deteriorating, while 2014 and 2016 benefited from the dual contributions of technological efficiency improvements and 
technological progress, with the exception of 2014, during which the contribution of the environmental performance index to the other three years was significantly less than that of the latter. Not only did technological efficiency deteriorate in 2006 and 2009, but cutting-edge technology was also degraded. In general, agricultural technological progress has played the most visible role in promoting the promotion of low-carbon agricultural productivity.

In promoting China's agricultural development, agricultural technological efficiency improvement plays a relatively small role, as its average annual growth rate is only $0.04 \%$. Agricultural technical efficiency improved in 2001, 2003, 2004, 2008, 2010, 2012, 2013, 2014, and 2016, but the rate of improvement was generally low, with the majority of the years improving within 3 percent and as low as 1 percent. The remaining years of 2000, 2002, 2005, 2006, 2007, 2009, 2011, and 2015 showed a deterioration in agricultural efficiency. In two of these years, this deterioration was greater than 2 percent. The evolutionary trajectory can still be roughly divided into three phases: 2000-2004 was a stage of fluctuation. Although the change in agricultural technology efficiency was more dramatic, the overall trend followed up-down cycle characteristics, and the final change was not significant. The period of 2004-2010 represented a relatively stable stage, and the inter-annual value of agricultural technology efficiency was maintained at about 1.0 with only small fluctuations. However, 2010-2016 was again a period of volatility. Although this period experienced large ups and downs, the final cumulative value of agricultural technology efficiency compared to 2010 indicated no significant change, and the largest fluctuations occurred in 2014 and 2011. The former agricultural technical efficiency value increased by $3.87 \%$ compared with the previous year, with the largest improvement rate in the calendar year, while the latter compared with the previous year's sharp decline of 4.06 percent. The latter was also the largest in the past year.

Figure 3 further analyzes the sources of changes in agricultural technology efficiency. The years of 2001, 2010, and 2013 were entirely dependent on improvements in pure technical efficiency, while scale efficiency deteriorated. The contribution of other previous years to agricultural technical efficiency was slightly higher than that of the latter, and the efficiency and scale efficiency of pure technology in $2000,2005,2006,2007$, and 2011 deteriorated. Although the role of the two factors was roughly the same, the overall scale efficiency in the improvement of agricultural technology efficiency was more significant. The average efficiency of 1.0010 indicates that the annual improvement in agricultural technology efficiency was $0.10 \%$.

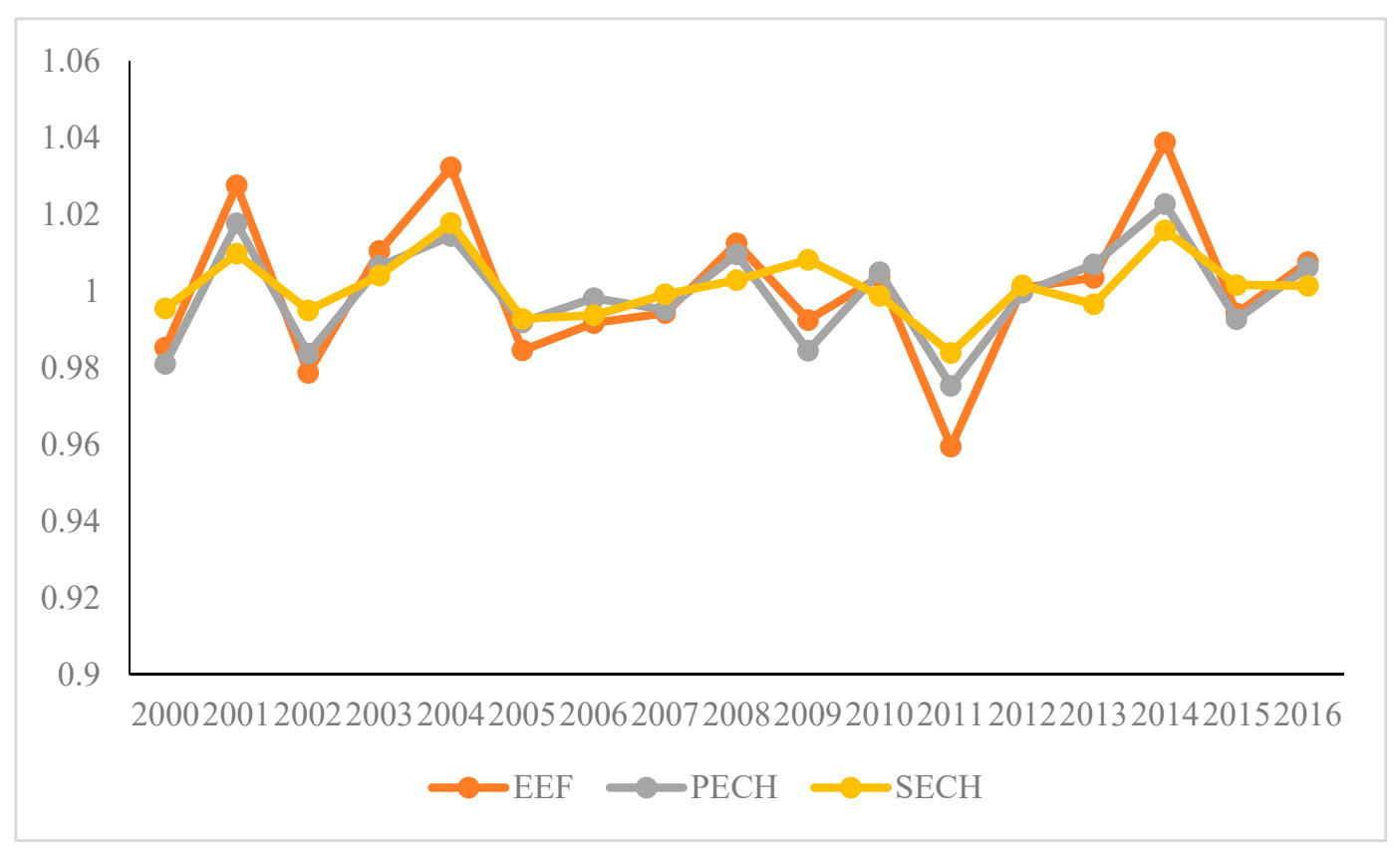

Figure 3. Sources of changes in the agricultural environment performance index. 
In comparison, the progress of agricultural technology has played the most significant role in promoting the performance of the agricultural environment in China, and its average annual growth rate has reached $0.76 \%$. Agricultural technologies progressed in 2000, 2002, 2005, 2007, 2008, 2010, $2011,2014,2015$, and 2016, and were generally significant at $2 \%$ or more, among which 9.25 percent, 4.87 percent, and 4.84 percent increases occurred in 2011, 2008, and 2000, respectively. Agricultural technologies degraded in 2012 and 2013, with some years showing degradation of more than 3 percent. In general, agricultural technology sometimes progressed and sometimes degraded, with a certain degree of irregularity. However, combined with the change characteristics, these developments can be roughly divided into five stages: The period of 2000-2002 was a smooth stage of ups and downs; although there were some fluctuations, the overall change was not large. The average annual growth rate was only $0.33 \%$, but because the period of study experienced a certain amount of ups and downs, the trend cannot be simply defined as "smooth". In 2002-2004, a period of continuous decline, agricultural technology deteriorated significantly for two consecutive years, with the degradation rates reaching 3.99\% and 7.43\%, respectively; 2004-2011 was a period of volatility and increases. Except for the small degradation of agricultural cutting-edge technology in 2006 and 2009, the other years showed a progressive trend. The average annual growth rate at this stage also reached $2.64 \%$, and the upward trend was more obvious. The years of 2011-2013 were again a sustained period of decline, with agricultural technology deteriorating for two consecutive years in 2012 and 2013 - by 3.20\% and $0.04 \%$, respectively, compared with the previous year. For the period of a continuous rise from 2013 to 2016, agricultural technology continued to improve for three consecutive years, with growth rates of $2.21 \%$, $2.06 \%$, and $2.82 \%$, respectively.

\subsection{Provincial Distribution of the Agricultural Environmental Performance Index}

The average agricultural environmental performance in 20 regions, including Beijing, Tianjin, Hebei, and Shanxi, was greater than 1 (Table 3), accounting for $66.67 \%$ of the total number of provincial administrative regions, while the average carbon emission performance of 10 regions, including Hainan, Tibet, and Qinghai, was less than 1, accounting for 33.33\% of the total number of provincial administrative regions. Beijing topped the list by an absolute margin. Beijing's environmental performance index mean was as high as 1.0721, and its overall efficiency in environmental performance increased at an average annual rate of $7.21 \%$. Anhui ranked second, with an average value of 1.0433 compared with Beijing. Positions 3-10 are held by Jiangsu (1.0416), Tianjin (1.0608), Shanghai (1.0367), Fujian (1.0367), Shandong (1.0335), Henan (1.0320), Guangdong (1.0298), and Zhejiang (1.0284). Correspondingly, Hainan had the lowest average low-carbon agricultural productivity at 0.8886 , while Tibet was second to last, with 0.9503 . The bottom 3-10 were determined to be Qinghai (0.9577) and Guizhou (0.9795), Inner Mongolia (0.9848), Yunnan (0.9914), Sichuan (0.9948), Jiangxi (0.9959), Ningxia (0.9985), and Hunan (0.9997). From a regional distribution perspective, the provinces with high average carbon emission performance are mainly distributed in the eastern and central regions of China, while the provinces with lower ACPTFP means are concentrated in the central and western regions of China.

The difference between China's environmental performance growth is more obvious among the provinces, where Beijing is the fastest, Gansu is the slowest, and Ningxia along with 10 other regions are declining. To show the characteristics of regional differences more clearly, combined with the absolute differences and distribution characteristics of their environmental performance values, 31 provinces (cities and districts) were divided into a "high-speed group", "fast group", "medium-speed group", "slow group", and "declining group". The "high-speed group" is a collection of provinces with significantly higher carbon emissions performance than other regions. By comparison, only Beijing, which meets this condition, has an environmental performance of 1.0721, which is significantly ahead of Anhui, which ranks second. The "medium speed group" refers to the collection of all regions with environmental performance levels above 1.00 but below 1.02, and the "declining group" refers to the collection of all regions with environmental performance below 1.0. 
Table 3. Average Agricultural Environmental Performance.

\begin{tabular}{|c|c|c|c|c|c|c|c|}
\hline Provinces & EFF & TECH & РECH & SECH & AEP & Ranking & Types of Change \\
\hline Beijing & 1 & 1.0721 & 1 & 1 & 1.0721 & 1 & High growth \\
\hline Tianjin & 1 & 1.0367 & 1 & 1 & 1.0367 & 4 & Rapid growth \\
\hline Hebei & 1.0078 & 1.0107 & 1 & 1.0078 & 1.0185 & 15 & Slow growth \\
\hline Shanxi & 1.0029 & 1.0017 & 1.0029 & 1.0001 & 1.0046 & 18 & Slow growth \\
\hline Inner Mongolia & 1 & 0.9848 & 1 & 1 & 0.9848 & 26 & Fall \\
\hline Liaoning & 1 & 1.0273 & 1 & 1 & 1.0273 & 11 & Medium-speed drop \\
\hline Jilin & 1 & 1.0005 & 1 & 1 & 1.0005 & 19 & Slow growth \\
\hline Heilongjiang & 1 & 1.022 & 1 & 1 & 1.022 & 13 & Medium-speed growth \\
\hline Shanghai & 1 & 1.0367 & 1 & 1 & 1.0367 & 5 & Rapid growth \\
\hline Jiangsu & 1 & 1.0416 & 1 & 1 & 1.0416 & 3 & Rapid growth \\
\hline Zhejiang & 1 & 1.0284 & 1 & 1 & 1.0284 & 10 & Medium-speed growth \\
\hline Anhui & 1.0151 & 1.0278 & 1.0114 & 1.0036 & 1.0433 & 2 & Rapid growth \\
\hline Fujian & 1 & 1.0335 & 1 & 1 & 1.0335 & 6 & Rapid growth \\
\hline Jiangxi & 0.9975 & 0.9986 & 0.9977 & 0.9999 & 0.9959 & 23 & Fall \\
\hline Shandong & 1.0089 & 1.0229 & 1 & 1.0089 & 1.032 & 7 & Rapid growth \\
\hline Henan & 1.0073 & 1.0224 & 1 & 1.0073 & 1.0298 & 8 & Medium-speed growth \\
\hline Hubei & 0.9944 & 1.0115 & 0.9928 & 1.0015 & 1.006 & 17 & Slow growth \\
\hline Hunan & 0.9994 & 1.0003 & 0.9972 & 1.0023 & 0.9997 & 21 & Fall \\
\hline Guangdong & 1 & 1.0284 & 1 & 1 & 1.0284 & 9 & Medium-speed growth \\
\hline Guangxi & 1 & 1.0103 & 1 & 1 & 1.0103 & 16 & Slow growth \\
\hline Hainan & 1 & 0.8886 & 1 & 1 & 0.8886 & 30 & Fall \\
\hline Chongqing & 1 & 0.9978 & 1 & 1 & 0.9978 & 24 & Fall \\
\hline Sichuan & 0.9971 & 0.9978 & 1 & 0.9971 & 0.9938 & 24 & Fall \\
\hline Guizhou & 0.9953 & 0.9842 & 0.9973 & 0.998 & 0.9795 & 27 & Fall \\
\hline Yunnan & 0.9877 & 1.0034 & 0.9884 & 0.9993 & 0.9914 & 25 & Fall \\
\hline Tibet & 1 & 0.9503 & 1 & 1 & 0.9503 & 29 & Fall \\
\hline Shaanxi & 1.0058 & 1.0152 & 1.0022 & 1.0036 & 1.0212 & 14 & Medium-speed growth \\
\hline Gansu & 0.9935 & 1.0016 & 0.9926 & 1.0008 & 1.0001 & 20 & Slow growth \\
\hline Qinghai & 1 & 0.9577 & 1 & 1 & 0.9577 & 28 & Fall \\
\hline Ningxia & 1 & 0.9985 & 1 & 1 & 0.9985 & 22 & Fall \\
\hline Xinjiang & 1 & 1.025 & 1 & 1 & 1.025 & 12 & Medium-speed growth \\
\hline
\end{tabular}


The "high-speed group" only includes Beijing, whose environmental performance is much higher than that of the other 30 regions. Beijing's superior performance is due to the area's higher level of agricultural production and agricultural material utilization efficiency. Moreover, Beijing's environmental performance is closely related to its industrial structure. The low proportion of animal husbandry in the area objectively reduces the carbon emission intensity of agriculture. In addition, Beijing has a good geographical location-its market encompasses the capital, which increased the market value of agricultural products to a certain extent.

The "fast group" includes Tianjin, Shanghai, Jiangsu, Anhui, Fujian, Shandong, and four other provinces along with two cities, mainly distributed in East China and North China. Among them, Tianjin and Shanghai are municipalities directly under the Central Government, where the level of agricultural production is higher, and agricultural materials have also been fully utilized. These factors coupled with the area's superior geographical location make agriculture relatively more efficient and have led to the area's rapid environmental performance growth. Shandong, as a traditional agricultural province and a strong province, has a high degree of organization in its agricultural production, a more reasonable industrial structure, and outstanding agricultural production benefits. Anhui and Fujian mainly benefit from their industrial structure, where the proportion of livestock and poultry farming industry is low, which objectively reduces the level of carbon emissions.

The "medium speed group" includes Liaoning, Heilongjiang, Zhejiang, Henan, Guangdong, Shaanxi, Xinjiang, and six other provinces plus one, mainly distributed in China's northeast, southeast coast, and northwest regions. Liaoning, Heilongjiang, and Henan are the main grain-producing areas of China, where the proportion of the planting industry is relatively high. However, Liaoning and Heilongjiang are limited by a relatively single variety of structures, low value-added agriculture. Henan is limited by its large population and limited land in ensuring that its output increases its agricultural material input, which also objectively exacerbated carbon emissions, resulting in environmental performance growth in these three areas only at a mid-range level. Zhejiang and Guangdong have a high degree of agricultural modernization. However, because they are not the main grain-producing provinces, and their economies are not focused on agriculture, their low-carbon agricultural development has been negatively affected to a certain extent. Shaanxi is mainly limited by its climatic conditions and soil conditions. Fortunately, less rice is grown in the area, so its environmental performance growth rate is still at a medium level. The high proportion of animal husbandry in Xinjiang objectively reduces the growth rate of the area's environmental performance.

The "slow group" includes Hebei, Shanxi, Jilin, Hubei, Guangxi, Gansu, and five other provinces plus one district. The regional distribution is relatively scattered, with the Northeast, North China, Central China, Southwest, and Northwest all involved. Hebei and Jilin are mainly subject to their crop planting structures, featuring mainly food crops and relatively few cash crops, which makes the economic and ecological benefits unsure. On the one hand, Hubei has a large rice planting area; on the other hand, it lacks agriculturally superior industries and competitive industries. Moreover, the area's deep processing is average, and its agricultural benefits are relatively poor. The natural conditions for agricultural production in Shanxi and Gansu are also relatively poor, and its industrial structure is average, resulting in low-carbon agricultural productivity at a low level. Although Guangxi's agricultural carbon sinks rank among the top in the country, the area's comprehensive agricultural production level is low, its carbon emissions are at a high level, and its agricultural production benefits are average, which has slowed the area's low-carbon agricultural development.

The "declining group" includes Inner Mongolia, Jiangxi, Hunan, Hainan, Sichuan, Chongqing, Guizhou, Yunnan, Tibet, Qinghai, and Ningxia; these areas are mainly located in Central China, Southwest China, and Northwest China. Two of these areas are mainly affected by their industrial structures. In these areas, the rice cultivation area is large, the proportion of cash crops is low, and the resulting carbon emission performance is also low. Inner Mongolia, Tibet, Qinghai, and Ningxia hold an important position in the animal husbandry industry, which makes their agricultural carbon emissions relatively high. The small scale of the planting industry in these areas reduces the output 
of carbon sinks, thus restricting agricultural development. For Sichuan and Guizhou, because of the locations of their cross-mountain areas, their ecological environment is relatively poor, and the level of their agricultural output is relatively low. Increases in Hainan's agricultural output mainly depend on increases in the agricultural material input, which belongs to typical high-carbon agriculture.

\section{Discussion}

Since 2000, China's environmental performance index growth has been slow. The average annual growth rate is only $0.80 \%$, and China's environmental performance index can be divided into three stages: a stable up and down phase, a volatility decrease phase, and a volatility increase phase. The period of 2000-2002 featured smooth ups and downs; despite certain fluctuations in the level of low-carbon agricultural development, cumulative productivity remained at about 0.98 overall. With the exception of a slight rebound in 2005, the period from 2002 to 2006 was a period of declining volatility; the environmental performance of all other years was below 1.0, indicating a downward trend compared with the previous year. The years of 2006-2016 were a period of rising volatility. The agricultural environmental performance level increased from 0.9256 to 1.1645 , an increase of 25.81\%. Except for 2009 and 2012, low-carbon agricultural productivity was higher than 1.0 in all other years. In terms of the sources of growth in environmental performance over the years, the years of 2001, 2003, 2004, 2012, and 2013 relied entirely on improvements in agricultural technical efficiency, with pure technical efficiency and scale efficiency playing roughly the same role, while technology was degraded. The years of 2000, 2002, 2005, 2007, 2011, and 2015 were entirely reliant on advances in agricultural technology, with technical efficiency deteriorating. In 2014 and 2016, the contributions of technological efficiency improvements and technological progress were significantly smaller than those of the other three years, except for 2014. In general, agricultural technological advances played the most visible role in promoting positive carbon emissions performance.

\section{Conclusions}

In the development process of China's agricultural modernization, the goals include: constructing a decision-making support system for structural reform on the supply side; linking the results of field research, observational data, simulations, and analyses of the moderate scale of modern agriculture using regional modern agricultural development models and model simulations; and exploring the key regulatory measures of agricultural modernization elements and policy optimizations in future situations, coupled with basic research innovation and a decision-making support system alongside the "New Normal State of China's Economy" and the "One Belt and Road Strategy". Modern agricultural research provides policy support and decision-making support for such topics as the coordinated development of urban and rural areas and the constraints of resources and the environment. To clarify the development path and international orientation of China's agricultural modernization, combined with theoretical and empirical investigations, we must take the following steps: clarify the constraints, target orientations, path selections, and policy formulations of China's agricultural modernization transformation; identify the path of agricultural modernization in typical countries around the world; study and predict the orientation of China's modern agricultural development level in the global development path; construct an index system that affects the transformation of agricultural modernization; explore the relationship between fairness and efficiency in the agricultural transformation mechanism; and put forward a path and policy plan for this agricultural transformation.

In this paper, we analyzed the agricultural modernization systems of several major countries along with China. When filtering the parameters of agricultural modernization research in developed countries, studies were found to focus on a single element, such as agriculture, industry, urbanization, or land use structure changes. There is a lack of comprehensive analyses of agricultural systems in China due to the influence of traditional agricultural development models. Thus, agricultural modernization system analysis and future path predictions are still in their infancy. To explore factors such as domestic and foreign resources and environmental policy, industrial structure 
adjustments, the urbanization process, land-use space-time, and differences in the process of agricultural modernization, we accomplished the following: we identified the key mechanisms affecting the development of agricultural modernization; we constructed a modern agricultural system analysis model that depicts the technical level, total factor productivity, resource environment, and social and economic indicators; and we studied the direction and path of the transformation of China's current and future agricultural modernization process. Under the constraints of resources and the environment, by using grain structural adjustments and cost-benefit analyses, we researched the current situation of a typical global country and China's modern agricultural development, built a national analysis database for the modern agricultural development model, and selected different modern agricultural cost-benefit accounting methods based on socio-economic, resource efficiency, and environmental conservation constraints to carry out multi-scenario forecasting, reveal the national modern agricultural scale-efficiency-benefit relationship, refine the most suitable and effective modern national agricultural model, and select a reasonable and effective food structure adjustment program. Constructing a comprehensive simulation model of modern agriculture in China faces several issues. China currently suffers from weak basic agricultural data, a low degree of data standardization, and policy gaps in agricultural supply-side reform. The application of big data technology was used to build an integrated simulation model for China's modern agricultural to capture consumption in real-time, track market changes, provide a personalized push (alongside other needs), and achieve domestic resource factor market optimization distribution and comprehensive decision-making, thereby facilitating the transformation of agricultural production from a "production-oriented" to a "consumer-oriented" model. In this way, a comprehensive analysis capacity under the constraints of modern agricultural production and resource environments is formed. When studying agricultural transformation and development, studies on the new normal of China's economy, the "Belt and Road Strategy", the coordinated development of urban and rural areas, and the constraints of resources and the environment, provide important opportunities for the expansion of agriculture and enable us to construct a new pattern of modern agricultural development. We suggest implementing special policy and decision-making support that is suitable for the development of China's agricultural modernization.

Author Contributions: Conceptualization, G.W.; methodology, Z.Q.; software, G.W.; validation, G.W. and X.D.; formal analysis, G.W.; investigation, G.W.; data curation, Z.Q.; writing-original draft preparation, G.W.; writing - review and editing, X.D.; visualization, X.D.; supervision, X.D. All authors have read and agreed to the published version of the manuscript.

Funding: This research was financially Supported by the Strategic Priority Research Program of Chinese Academy of Sciences, (Grant No. XDA23070402), the Youth Fund Project of the Humanities and Social Science Program of Ministry of Education, China (NO. 18YJC630174), Program for the Philosophy and Social Sciences Research of Higher Learning Institutions of Shanxi(2018-244) and National Natural Science Foundation of China (72003111).

Conflicts of Interest: The authors declare no conflict of interest.

\section{References}

1. Qian, X.; Ren, R.; Wang, Y.; Guo, Y.; Fang, J.; Wu, Z.D.; Liu, P.L.; Han, T.R. Fighting against the common enemy of COVID-19: A practice of building a community with a shared future for mankind. Infect. Dis. Poverty 2020, 9, 1-6. [CrossRef]

2. Johansen-Berg, H. Human connectomics-What will the future demand? Neuroimage 2013, 80,541-544. [CrossRef]

3. Rosa, W. Transforming Our World: The 2030 Agenda for Sustainable Development. In A New Era in Global Health; Springer Publishing Company: Cham, Switzerland, 2018. [CrossRef]

4. Morton, S.; Pencheon, D.; Squires, N. Sustainable Development Goals (SDGs), and their implementation. Br. Med. Bull. 2017, 124, 81-90. [CrossRef] [PubMed]

5. Kanza, P.; Vitale, J. Agriculture in Developing Countries and the Role of Government: Economic Perspectives; AAEA \& WAEA Joint Annual Meeting, Agricultural and Applied Economics Association: San Franciso, CA, USA, 2015.

6. Sanders, R. A market road to sustainable agriculture? Ecological agriculture, green food and organic agriculture in China. Dev. Chang. 2006, 37, 201-226. [CrossRef] 
7. International Fund for Agricultural Development; UNICEF; World Food Programme; World Health Organization. The State of Food Security and Nutrition in the World: Safeguarding Against Economic Slowdowns and Downturns; FAO: Rome, Italy, 2019; ISBN 978-92-5-131570-5.

8. Chai, Q.; Gan, Y.; Turner, N.C.; Zhang, R.Z.; Yang, C.; Niu, Y.; Siddique, K.H.M. Water-saving innovations in Chinese agriculture. In Advances in Agronomy; Elsevier: Amsterdam, The Netherlands, 2014.

9. Garnaut, R.; Song, L.; Fang, C. (Eds.) China's 40 Years of Reform and Development: 1978-2018; ANU Press: Canberra, Australia, 2018. [CrossRef]

10. Yu, J.; Wu, J. The sustainability of agricultural development in China: The agriculture-environment nexus. Sustainability 2018, 10, 1776. [CrossRef]

11. Diao, X.; Silver, J.; Takeshima, H. Agricultural Mechanization and Agricultural Transformation; International Food Policy Research Institute: Washington, DC, USA, 2016.

12. Dimitri, C.; Effland, A.; Conklin, N. The 20th century transformation of U.S. agriculture and farm policy/Carolyn Dimitri, Anne Effland, and Neilson Conklin. Transformation 2005, 1-13.

13. Hisano, S.; Akitsu, M.; McGreevy, S.R. Revitalising rurality under the neoliberal transformation of agriculture: Experiences of re-agrarianisation in Japan. J. Rural. Stud. 2018, 61, 290-301. [CrossRef]

14. Mueller, B.; Mueller, C. The political economy of the Brazilian model of agricultural development: Institutions versus sectoral policy. Q. Rev. Econ. Financ. 2016, 62, 12-20. [CrossRef]

15. Jiao, X.Q.; Mongol, N.; Zhang, F.S. The transformation of agriculture in China: Looking back and looking forward. J. Integr. Agric. 2018, 17, 755-764. [CrossRef]

16. Jiang, L.; Wu, F.; Liu, Y.; Deng, X. Modeling the impacts of urbanization and industrial transformation on water resources in China: An integrated hydro-economic cge analysis. Sustainability 2014, 6, 7586-7600. [CrossRef]

17. Lopez, R.A.; He, X.; De Falcis, E. What Drives China's New Agricultural Subsidies? World Dev. 2017, 93, 279-292. [CrossRef]

18. Jiao, X.Q.; He, G.; Cui, Z.L.; Shen, J.B.; Zhang, F.S. Agri-environment policy for grain production in China: Toward sustainable intensification. China Agric. Econ. Rev. 2018, 10, 78-92. [CrossRef]

19. Conrad, E.; Cassar, L.F. The Environmental Performance Index. In Routledge Handbook of Sustainability Indicators; Routledge: London, UK, 2019.

20. Mori, K.; Christodoulou, A. Review of sustainability indices and indicators: Towards a new City Sustainability Index (CSI). Environ. Impact Assess. Rev. 2012, 32, 94-106. [CrossRef]

21. Zhou, P.; Ang, B.W.; Poh, K.L. Slacks-based efficiency measures for modeling environmental performance. Ecol. Econ. 2006, 60, 111-118. [CrossRef]

22. Siddig, A.A.H.; Ellison, A.M.; Ochs, A.; Villar-Leeman, C.; Lau, M.K. How do ecologists select and use indicator species to monitor ecological change? Insights from 14 years of publication in Ecological Indicators. Ecol. Indic. 2016, 60, 223-230. [CrossRef]

23. Rasmussen, P.E.; Goulding, K.W.T.; Brown, J.R.; Grace, P.R.; Janzen, H.H.; Korschens, M. Long-term agroecosystem experiments: Assessing agricultural sustainability and global change. Science 1998, 282, 893-896. [CrossRef]

24. Picazo-Tadeo, A.J.; Gómez-Limón, J.A.; Reig-Martínez, E. Assessing farming eco-efficiency: A Data Envelopment Analysis approach. J. Environ. Manag. 2011, 92, 1154-1164. [CrossRef]

25. Song, M.L.; Fisher, R.; Wang, J.L.; Cui, L.B. Environmental performance evaluation with big data: Theories and methods. Ann. Oper. Res. 2018, 270, 459-472. [CrossRef]

26. Sidhoum, A.A.; Serra, T.; Latruffe, L. Measuring sustainability efficiency at farm level: A data envelopment analysis approach. Eur. Rev. Agric. Econ. 2020, 47, 200-225. [CrossRef]

27. Holzworth, D.P.; Snow, V.; Janssen, S.; Athanasiadis, I.N.; Donatelli, M.; Hoogenboom, G.; White, J.W.; Thorburn, P. Agricultural production systems modelling and software: Current status and future prospects. Environ. Model. Softw. 2015, 72, 276-286. [CrossRef]

28. Färe, R.; Grosskopf, S.; Pasurka, C.A. Environmental production functions and environmental directional distance functions. Energy 2007, 32, 1055-1066. [CrossRef]

29. Xu, R.; Wu, Y.; Huang, Y. Measurement and convergence of carbon productivity across Shanghai's manufacturing sectors. Int. J. Clim. Chang. Strateg. Manag. 2020, 12, 369-387. [CrossRef]

30. Fried, H.O.; Knox Lovell, C.A.; Schmidt Shelton, S. Efficiency and Productivity. In The Measurement of Productive Efficiency and Productivity Change; Oxford University Press: Oxford, UK, 2008; ISBN 9780199870288. 
31. Camanho, A.S.; Dyson, R.G. Data envelopment analysis and Malmquist indices for measuring group performance. J. Product. Anal. 2006, 26, 35-49. [CrossRef]

32. Ludena, C.E. Agricultural Productivity Growth, Efficiency Change and Technical Progress in Latin America and the Caribbean. SSRN Electron. J. 2012. [CrossRef]

33. Fei, R.; Lin, B. Energy efficiency and production technology heterogeneity in China's agricultural sector: A meta-frontier approach. Technol. Forecast. Soc. Chang. 2016, 109, 25-34. [CrossRef]

Publisher's Note: MDPI stays neutral with regard to jurisdictional claims in published maps and institutional affiliations.

(C) 2020 by the authors. Licensee MDPI, Basel, Switzerland. This article is an open access article distributed under the terms and conditions of the Creative Commons Attribution (CC BY) license (http://creativecommons.org/licenses/by/4.0/). 